\title{
T Cell Delivery of Nanoparticles-Bound Anti-CD20 Monoclonal Antibody: Successful B Cell Depletion in the Spinal Cord during Experimental Autoimmune Encephalomyelitis
}

\author{
Alberto Carnasciali ${ }^{1}$. Roberta Amoriello ${ }^{1}$ Elena Bonechi ${ }^{1}$ - Alessio Mazzoni ${ }^{1}$ - Costanza Ravagli ${ }^{2}$. Saer Doumett ${ }^{2}$. \\ Laura Cappiello ${ }^{2} \cdot$ Mario Milco D'Elios $^{1} \cdot$ Giovanni Baldi $^{2} \cdot$ Clara Ballerini $^{1}$ (D)
}

Received: 20 November 2019 / Accepted: 1 June 2020

(C) Springer Science+Business Media, LLC, part of Springer Nature 2020

\begin{abstract}
We developed a nanotechnology based-cell mediated drug delivery system by loading myelin antigen-specific $\mathrm{T}$ cells with nanoparticles bound to anti-CD20 monoclonal antibody. Anti-CD20 antibody is a current treatment (ocrelizumab) for multiple sclerosis (MS), a chronic, inflammatory and autoimmune disease of the central nervous system (CNS). CD20-depletion has been associated with efficacy in active relapsing and progressive MS, but may not efficiently target inflammatory cells compartmentalized in the CNS. In our work, the intravenous transfer of T cells containing nanoparticle-anti-CD20 complex in mice causes B cell depletion in the spleen and in the brain, whereas the injection of anti-CD20 alone depletes B cells only in the spleen. Testing this system in Experimental Autoimmune Encephalomyelitis (EAE), animal model of MS, we found that spinal cord B cell depletion ameliorates the disease course and pathology.
\end{abstract}

Keywords Nanoparticles loaded T cells $\cdot$ Anti-CD20 $\cdot$ Drug delivery $\cdot$ EAE

\section{Introduction}

Nanoparticles-based drug delivery systems (NDDS) have been a point of interest because of their low cost, good biodegradability, ease of synthesis and for their capability to load and release active molecules beyond the blood-brain barrier (BBB) (Nance et al. 2014; Zhang et al. 2016). Furthermore, the chemical functionalization of NDDS has been extensively exploited to enhance central nervous system (CNS) cargoes concentration (Zhou et al. 2018).

Electronic supplementary material The online version of this article (https://doi.org/10.1007/s11481-020-09931-w) contains supplementary material, which is available to authorized users.

Clara Ballerini

clara.ballerini@unifi.it

1 Department of Clinical and Experimental Medicine, University of Florence, Viale Gaetano Pieraccini 6, 50125 Florence, Italy

2 Research Center Colorobbia, Cericol, Colorobbia Consulting, Via Pietramarina 123, 50053, Vinci, Florence, Italy
However, one of the major issues in the use of NDDS is the poor ability of these materials to specifically target the site of interest ( $\mathrm{Li}$ et al. 2018), since a systemic treatment dispersion is generally observed. To overcome this hurdle, cell-mediated NDDS have been developed, in which immune cells are suited as "Trojan horse" and loaded with drugs of interest to release them beyond the BBB (Batrakova et al. 2011; Ballerini et al. 2015). Indeed, the greatest obstacle to the access of drugs to the CNS is the presence of physiological barriers, such as the $\mathrm{BBB}$ and the blood-spinal cord barrier (BSCB) (Goyal et al. 2014; Batrakova and Kabanov 2013). Since only small lipid soluble molecules with a molecular weight $<400 \mathrm{Da}$ are allowed to cross the BBB, a large amount of treatments used for neurological morbidities are ineffective when this barrier is closed (Dong 2018); thus, new strategies for an effective brain drug delivery system are strongly needed.

In previous work, we demonstrated that iron-oxide nanoparticles (NBR) enter $T$ cells in vitro without exerting toxic effects. Moreover, we showed that nanoparticle-loaded T cells efficiently migrate and release NBR to the CNS parenchyma when i.v. transferred either into naïve recipient mice, in which the BBB is intact, or in mice characterized by an impaired $\mathrm{BBB}$ due to the induction of Experimental Autoimmune 
Encephalomyelitis (EAE), animal model of Multiple Sclerosis (MS) (D’Elios et al. 2018).

Here, we developed a T cell mediated drug delivery system by loading MOG35-55 antigen specific T cells with NBR nanoparticles functionalized on their surface with the monoclonal antibody anti-CD20 (NBR-anti-CD20). We tested in vivo this T cell-NBR-anti-CD20 complex for its capability to deplete B cells in the periphery and in the CNS of mice during EAE.

Our work showed that the i.v. transfer of autoantigen specific T cells loaded with NBR-anti-CD20 depletes B cells in the spleen and in the spinal cord of mice, whereas anti-CD20 alone depletes B cells only in the spleen.

\section{Results}

\section{T Cells Are Successfully Loaded with NBR-Anti-CD20 Complex}

In previous work, we showed that pristine NBR enter T cells upon $2 \mathrm{~h}$ of incubation (D'Elios et al. 2018). In the present study, we first investigated whether NBR functionalized with the antibody anti-CD20 are also able to enter T lymphocytes. Figure 1a shows that, after $2 \mathrm{~h}$ of incubation, around $85 \%$ (see Methods) of $\mathrm{T}$ cells are loaded with nanoparticles. Furthermore, more than $88 \%$ of loaded $\mathrm{T}$ cells are alive (Fig. 1b). We conclude that NBR-anti-CD20 complex is quickly loaded by $\mathrm{T}$ cells in the absence of clear signs of cell toxicity.

\section{T Cells Loaded with NBR-Anti-CD20 Complex Deplete Peripheral B Cells}

A second set of experiments was designed to compare the ability of the neutralizing anti-CD20 antibody to in vivo deplete B cells when complexed to NBR and injected i.v. by passive transfer of $\mathrm{T}$ cells containing the NBR-anti-CD20 complex.

We used two groups of animals that were injected i.v. (see Methods) with the anti-CD20 antibody alone or with T cells loaded with NBR-anti-CD20 complex. After 9 and 17 days from the injection, we collected the spleens of the treated mice in order to evaluate the $\mathrm{CD} 19^{+}$cells depletion and compared the results among the groups of animals.

Notably, after 9 days from the injection these values are comparable, suggesting that NBR-anti-CD20 loaded T cells may migrate to the spleen and efficiently release their nanoparticle-cargo containing the monoclonal antibody; furthermore, as expected, no CD19+ depletion is observed in control groups (Fig. 2a, c). In a second time point, after 17 days, spleen percentage of CD19+ cells was of 36.5 in
NBR-anti-CD20-treated mice and of 30.3 in anti-CD20treated mice (Fig. 2b).

\section{Iron-Oxide Specific Staining Confirms NBR Delivery in the CNS}

Crucial to our hypothesized exploitation of $\mathrm{T}$ cells in their ability to deliver their nanoparticle-cargoes into the CNS, in particular in diseased animals, we previously showed that $\mathrm{T}$ cells $\left(\mathrm{CD}^{+}\right)$loaded with NBR reached the spinal cord in either naïve and EAE mice (D'Elios et al. 2018).

Here, we confirm this finding, showing the presence of NBR nanoparticles in the CNS of NBR-anti-CD20 treated EAE mice (Fig. 3c, d). NBR were not detected in PBStreated mice, used as negative controls (Fig. 3a, b).

\section{NBR-Anti-CD20 Complex Loaded into T Cells Depletes B Cells in Mice Spinal Cord}

We decided to further exploit our EAE model to verify whether the injection of anti-CD20 antibody alone or as a nanoparticle-cargo in $\mathrm{T}$ cells succeeded in depleting $\mathrm{B}$ cells within the CNS. This is particularly interesting since the pathogenic role of $\mathrm{B}$ cells in $\mathrm{MOG}_{35-55}$-induced EAE is a matter of debate. Besides, B cells form part of the CNS infiltrate during the disease, thus $\mathrm{MOG}_{35-55}$-induced EAE represents a unique model to investigate the efficacy of the anti-CD20mediated B cell depletion in the CNS.

In Fig.3e-o, we report the quantification of the amount of B cells in the spinal cord infiltrates in all the experimental groups: Fig. 3e) animals treated with PBS; Fig. 3f) animals treated with $\mathrm{T}$ cells loaded with NBR-anti-CD20; Fig. 3g) animals treated with anti-CD20 and Fig. 3h) animals treated with T cells loaded with NBR-isotype (NBR-ISO) control.

We found differences among groups, with the presence of B cells aggregates (Fig. 3i-n) within the cellular infiltrates in the subarachnoid space and in the white matter of control groups, whereas NBR-anti-CD20 group exhibited only sparse $B$ cells that generally failed to aggregate (Fig. $3 \mathrm{f}, 1$ ). We then quantified B220 $0^{+}$cells $/ \mathrm{mm}^{2}$ in spinal cords of each group of mice (Fig. 4o). Results show that a significant $(p<0.001$; $p<0.0001)$ B cell depletion is present in NBR-anti-CD20treated animals compared to all other groups. We did not find any significant difference among the other experimental groups. These data strongly support the hypothesis that NBR-anti-CD20 complex loaded in T cells efficiently migrate in the spinal cord and to release the anti-CD20 antibody, which depletes B cells in spinal cord infiltrates. Conversely, anti-CD20 alone might not reach the CNS in a sufficient therapeutic concentration. Of note, NBR-antibody complexes were prepared using a concentration of anti-CD20 equal to the concentration of anti-CD20 antibody alone (see Methods). 
Fig. 1 Evaluation by

fluorescence microscopy and viability of $\mathrm{T}$ cells loaded with fluorescent NBR-anti-CD20. a Fluorescence microscopy of T cells (isolated from naïve C57BL/ 6 mice) after the incubation for $2 \mathrm{~h}$ with fluorescent NBR-antiCD20. Upper pictures show DAPI staining for cells nuclei (in blue) and NBR fluorescence (fluorescein 488, in green). Lower pictures show $\mathrm{CD} 3+\mathrm{T}$ cells (in red) and the merged image (scale bar $=20 \mu \mathrm{m} ; 40 \mathrm{X}$ ). b Analysis by flow cytometry of the viability of $T$ cells incubated with fluorescent NBR-anti-CD20 for $2 \mathrm{~h}$ and labelled with propidium iodide (PI) to detect necrotic cells. In the dot plot, the percentage of necrotic $\mathrm{T}$ cells loaded with fluorescent NBR-anti-CD20 (NBR FluoaCD20 + PI+) is reported in the gate Q2. One experiment representative of three independent ones is shown a

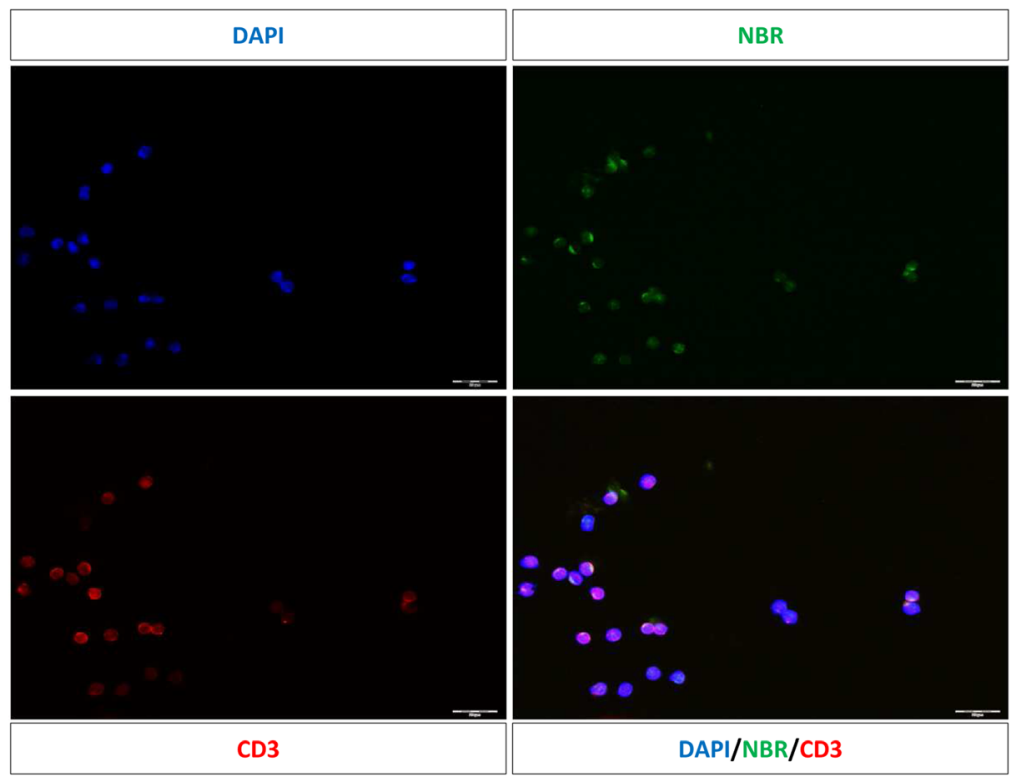

b

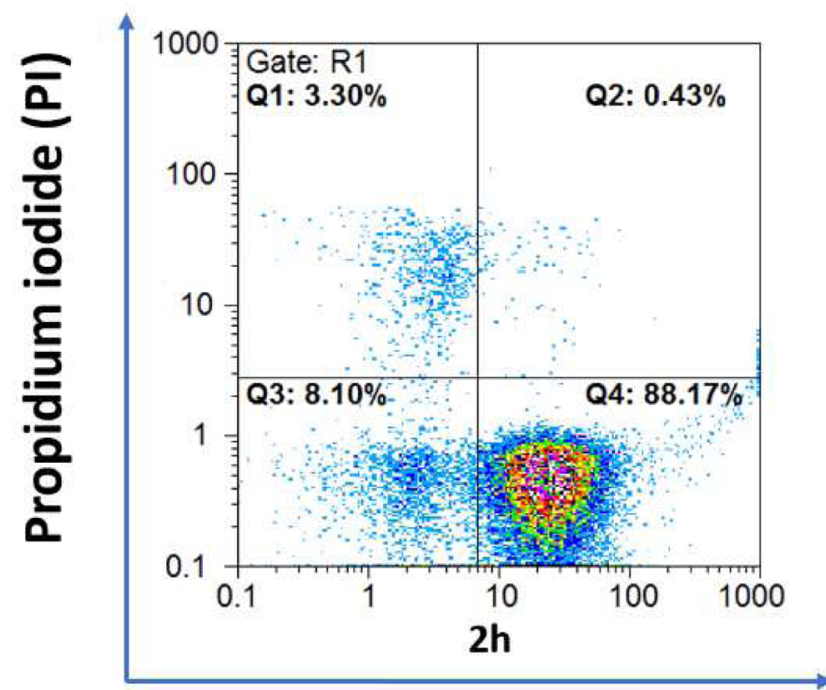

NBR Fluo-anti CD20

\section{Spinal Cord B Cell Depletion Ameliorates EAE Course}

Next, we compared the clinical course of the disease among the different groups of animals to validate this nanoparticle-mediated therapeutic strategy. Despite the controversial role of $\mathrm{B}$ cells in $\mathrm{MOG}_{35-55}$ EAE model, we document a milder clinical course of the disease when $\mathrm{B}$ cells are depleted from the spinal cord. In Fig. 4, a comparison among the clinical score of the four groups is depicted: NBR-anti-CD20-treated mice (Fig. 4, blue line) display a significant $(p<0.05)$ lower disability when compared to PBS-treated animals (Fig. 4, yellow line).
This finding strengthens the hypothesis that the route of neutralizing antibody administration is crucial to ameliorate EAE.

\section{NBR-Anti-CD20 Treatment Limits Spinal Cord Demyelination and Infiltrates}

Accordingly with clinical findings, the evaluation of inflammatory infiltrates in the CNS of EAE mice assessed by histological H\&E staining (Fig. 5a, first row) highlights the differences between NBR-anti-CD20-treated 
a

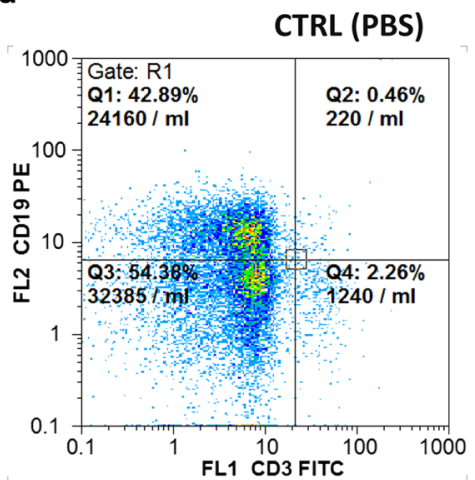

9 days post injection

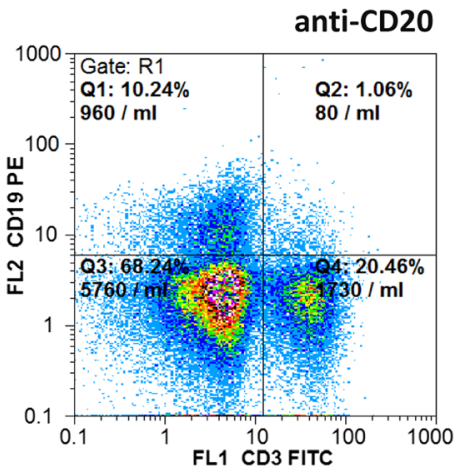

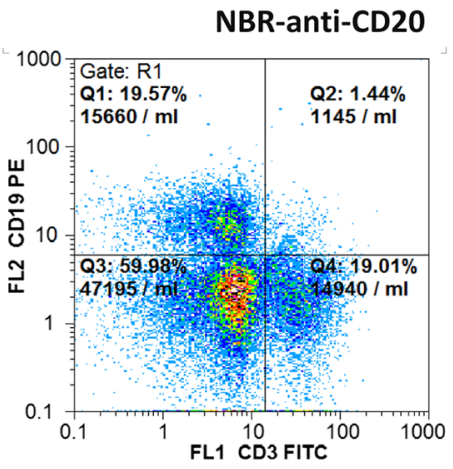

17 days post injection

b
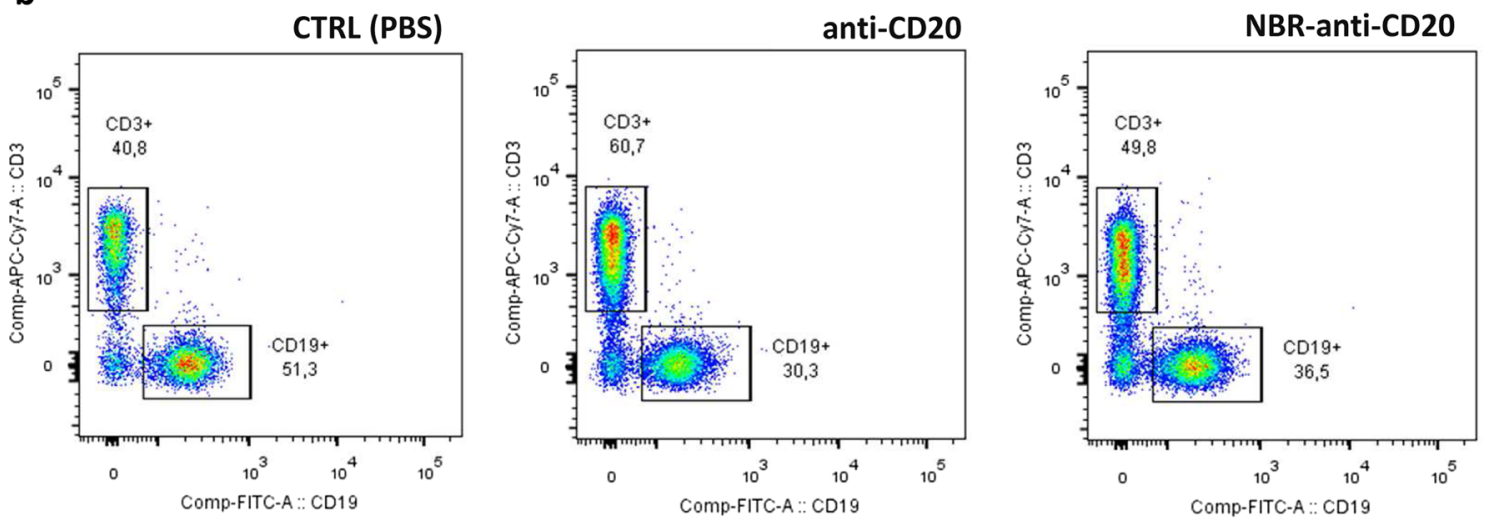

C

9 days post injection

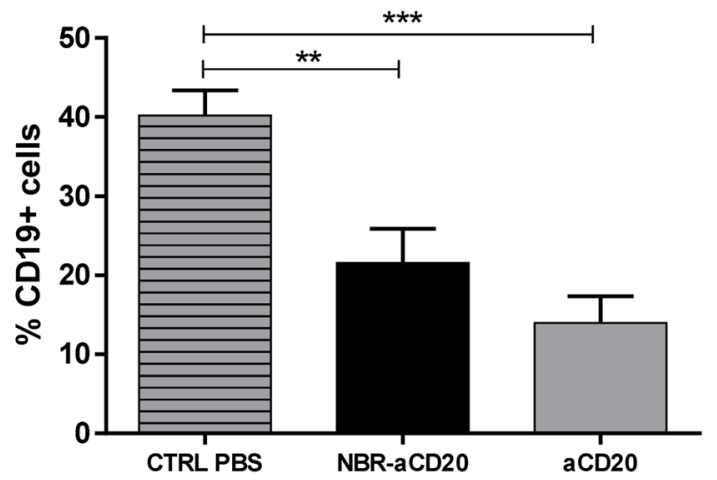

Fig. 2 Spleen B cells depletion in mice analyzed by flow cytometry after 9 and 17 days from treatments. a Flow cytometry dot plots report the percentages of CD19+ (gate Q1 in each plot) and CD3+ cells (gate Q4 in each plot) within the spleen of a mouse from control group (PBS-treated; left plot), anti-CD20 group (middle plot) and from NBR-anti-CD20 group (right plot) at 9 days post injection. b Flow cytometry dot plots report the percentages of CD19+ and CD3+ cells within the spleen of a mouse from control group (PBS-treated; left plot), anti-CD20 group (middle plot) and

mice and the other groups in terms of number, extension and tissue distribution of cell infiltrates. from NBR-anti-CD20 group (right plot) at 17 days post injection. c Graph reports the percentage of CD19+ cells, analyzed by flow cytometry, at 9 days post injection in CTRL mice group (PBS-treated), NBR-antiCD20-treated mice and anti-CD20-treated mice. One experiment of three independent ones is shown. Each group consists in three-four mice. Mean \pm SEM is reported. Mann-Whitney statistical test was used $(* * p<0.01 ; * * * p<0.001)$

In NBR-anti-CD20-treated mice, infiltrates in spinal cord sections are small, rare and display a perivascular location. 
Based on these differences, we assigned a histological score (see Methods) (Giuliani et al. 2005) to provide a semiquantitative evaluation (Fig. 5b).

Our results show that the histological score attributed to NBR-anti-CD20-treated mice is significantly $(p<0.01)$ lower than the other groups; specifically, there is a smaller amount of inflammatory foci and a less parenchymal infiltration.

In Fig. 5a (second row), we report an example of LFB/PAS staining, used to assess the state of spinal cord demyelination, a hallmark of the disease. Results show that NBR-anti-CD20treated mice present less demyelination. Accordingly, the demyelination score (see Methods) is lower $(p<0.05)$ in NBRanti-CD20-treated mice compared to the other groups (Fig. $5 b)$.

In addition, the evaluation of astrogliosis, performed by glial fibrillary acidic protein (GFAP, a cytoskeletal marker for astroglia) labelling revealed a limited astrogliosis within the NBR-anti-CD20 group (Fig. 5a, third row) compared to others. We may conclude that NBR-anti-CD20-treatment, and not anti-CD20 alone, ameliorates EAE pathology.

\section{The Spinal Cord of NBR-Anti-CD20-Treated Mice Shows a Higher Percentage of Neurons and no Axonal Damage}

We investigated the number of $\mathrm{NeuN}+$ cells and the axonal damage in the spinal cord of EAE mice and then compared the results among the four groups of treatments. The analysis of $\mathrm{NeuN}+$ cells by immunofluorescence (Fig. 6a) and the paired quantification by manual count (Fig. 6b) shows a significantly higher NeuN+ percentage in NBR-anti-CD20-treated EAE mice compared to all the other groups (CTRL, anti-CD20 and NBR-ISO).

In parallel, the qualitative evaluation of the axonal damage by Bielschowsky staining (Fig. 7) shows a generally better axonal state in the spinal cord of NBR-anti-CD20-treated mice compared to the other groups.

\section{Autoreactive T Cell Transfer Does Not Alter the Peripheral Production of pro-Inflammatory Cytokines during EAE}

To gain insight into the effect of NBR-anti-CD20 loaded T cells during EAE, we then investigated the levels of proinflammatory cytokines involved in EAE pathogenesis (IFN- $\gamma$ and IL-17 (D'Elios et al. 2018)) from cells isolated from mice draining lymph nodes after in vitro stimulation (Fig. 8a-d).

Our data do not show a difference between IFN- $\gamma$ (Fig. 8a, b) and IL-17 (Fig. 8c, d) production among groups, indicating that autoreactive $\mathrm{T}$ cells injection is not altering the production of pathogenic cytokines from peripheral encephalitogenic T cells. Furthermore, EAE amelioration does not follow a decreased peripheral release of pathogenic cytokines.

\section{Spleen Cells from NBR-Treated Mice Show a Lower In Vitro Proliferative Response}

We next evaluated the ex vivo proliferative response of splenocytes from EAE mice (Fig. 8e). Results show a significantly $(p<0.05 ; p<0.01)$ reduced proliferation (about $1.5-2$ folds lower) in NBR-anti-CD20- and NBR-ISO-treated mice compared to PBS- and anti-CD20-treated groups after in vitro cells stimulation with $\mathrm{MOG}_{35-55}$.

\section{Discussion and Conclusion}

In the present study, we show that nanoparticles bound to the neutralizing anti-CD20 antibody enter T cells without exerting any toxic effect (Fig. 1) and, once tested in vivo, efficiently mediate B cell depletion within mice spleen (Fig. 2), as it happens after the injection of anti-CD20 alone. Furthermore, our study demonstrates that $\mathrm{T}$ cells loaded with NBR-antiCD20 complex migrate to the CNS during EAE and significantly reduces the number of $\mathrm{B}$ cells in spinal cord infiltrates (Fig. 3), whereas the injection of anti-CD20 alone is ineffective. Finally, we found that this novel, cell-mediated drug delivery system ameliorates the clinical course of EAE (Fig. 4), preserving neurons (Fig. 6) and the axonal state (Fig. 7) of the CNS of EAE mice.

Developing a complex $\mathrm{T}$ cell mediated drug delivery system to target $\mathrm{B}$ cells in the CNS, we demonstrated that $\mathrm{T}$ cells are an efficient mean of drug delivery in the brain, which is normally difficult to target. Indeed, the percentage of depleted $B$ cell in mice spleen (Fig. 2d) suggests that $T$ cells loaded with NBR-anti-CD20 partially release the cargo in the periphery, where injected cells arrive through the blood flow, eliciting a peripheral B cell depletion as much as anti-CD20 alone. In our work, the peripheral depletion of B lymphocytes does not impact the clinical course of $\mathrm{MOG}_{35-55}$ induced EAE, accordingly to previous findings reported in Weber et al. (2010) and Matsushita et al. (2008). In these studies, authors investigated the possible role of B cells in EAE pathogenesis and demonstrated that mice treated with anti-CD20 exhibit a worsening or an improvement of symptoms, depending on the adopted protocol of immunization and treatment. Our observations suggest that in the chronic EAE model the peripheral $\mathrm{B}$ cell depletion is ineffective during the disease onset. Since we did not observe any clinical worsening of $\mathrm{EAE}$, it is tempting to speculate that $\mathrm{B}$ cells have no regulatory action in the $\mathrm{MOG}_{35-55}$-induced $\mathrm{EAE}$ autoimmune reaction at 10 days post-immunization (d.p.i.). Looking at the data of infiltrates, we have to underline that the number of infiltrates 

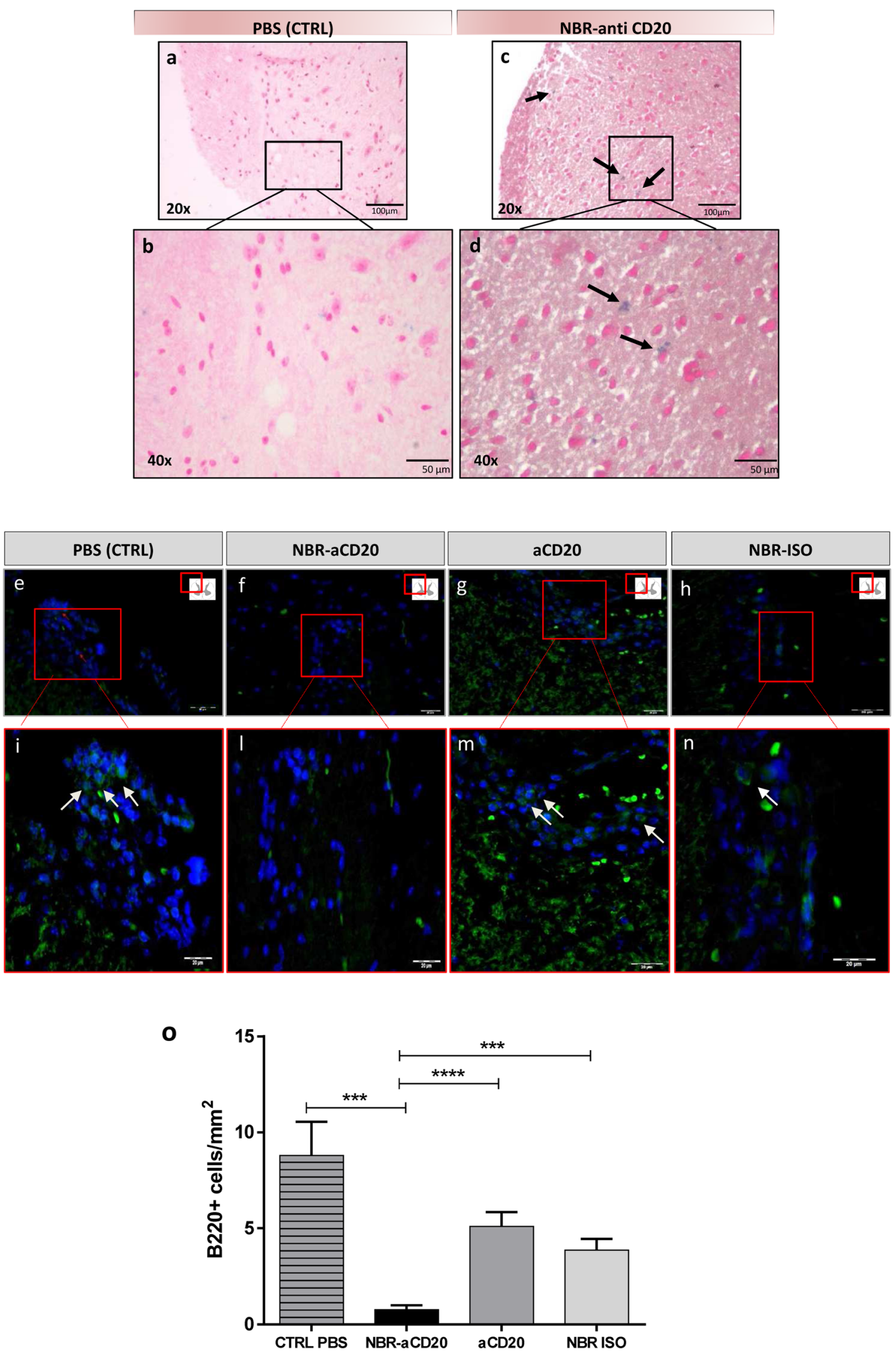
Fig. 3 Spinal cord NBR detection and B cell quantification. Figures a-d show spinal cord sections of EAE mice observed by optical microscopy after Perls staining, specific for iron-oxide, to detect the presence of NBR. Two 40X magnifications (b, $\mathbf{d}$; scale bar $=100 \mu \mathrm{m}$ ) of two 20X spinal cord sections (a, c; scale bar $=50 \mu \mathrm{m})$ are shown. Blue = iron-oxide deposits; red = nuclei; pink $=$ cytoplasm. Black arrows indicate iron-oxide NBR. e-n Representative images of fluorescent microscopy are showed in the panel above. Spinal cords from: PBS mice (e, i), NBR-anti-CD20 $(\mathbf{f}, \mathbf{l})$, anti-CD20- (g, m) and NBR-ISO- $(\mathbf{h}, \mathbf{n})$ treated mice. Sections were labelled with FITC-B220 anti-mouse monoclonal antibody (in green) and DAPI (cell nuclei, in blue). Scale bar $=20 \mu \mathrm{m}$; magnifications $=20 \mathrm{X}$ (e, $\mathbf{f}$, g, h) and 40X (i, l, m, n). Columns in the graph (o) represent B cell amounts per $\mathrm{mm}^{2}$ in spinal cord sections (approximately, $1 \mathrm{~mm}^{2}$ covers half spinal cord slice) in NBR-anti-CD20- (left column) and anti-CD20treated mice (right column). At least 15 spinal cord's slices for two mice of each group were evaluated. Unpaired t-test statistical test was performed. Mean \pm SEM of two independent experiments is reported. Mann-Whitney statistical test was used $(* * * \mathrm{p}<0.001 ; * * * * p<0.0001)$

and the presence of B cells in CNS infiltrates are two aspects not forcedly directly related. We may hypothesize that reduction of infiltrates in these experiments has beneficial effects when B cells are reduced. On the other hand, other experimental features may increase brain infiltrates in term of numbers and components comparing to PBS treated mice: first, the B cell depletion, when it is limited at the periphery; second, the inoculation of autoreactive $\mathrm{T}$ cells carrying the isotype control, although not affecting the EAE clinical score, may increase the cells able to migrate into the parenchyma.

Cytokines produced in vitro by $\mathrm{MOG}_{35-55}$ stimulated lymph nodes $\mathrm{T}$ cells are not significantly modulated by the treatments (Fig. 8a-d). In light of this result, we may conclude that peripheral $\mathrm{MOG}_{35-55}$-primed $\mathrm{T}$ cells are not shifted towards a different phenotype, e.g. inflammatory (Th1) or

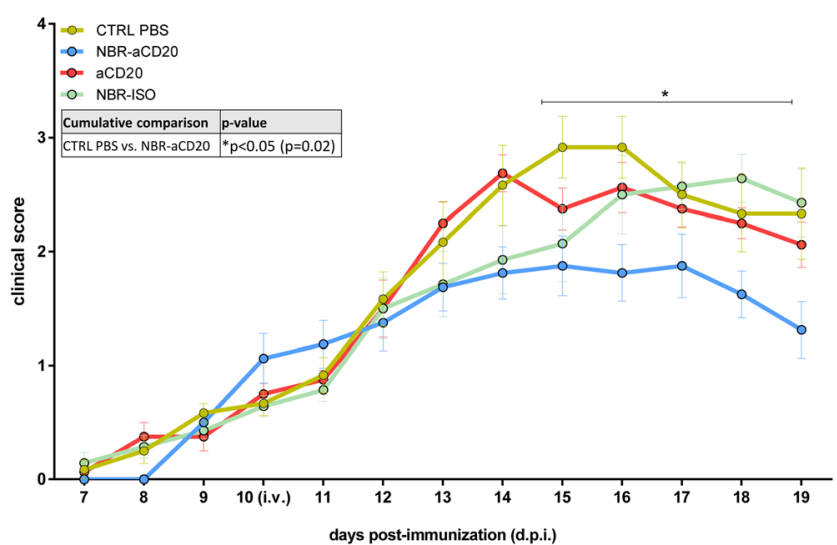

Fig. 4 EAE clinical scores. Graph reports EAE mice clinical score, evaluated daily according to following scale: 0 normal mouse, no overt signs of disease; 1 limp tail or hind limb weakness but not both; 2 limp tail and hind limb weakness; 3 partial hind limb paralysis; 4 complete hind limb paralysis; 5 moribund state; death by EAE. NBR loaded T cells were i.v injected at 10 days post-immunization d.p.i. Mice were sacrificed at 19 d.p.i. One experiment of two independent ones is shown. Each group consists in three-four mice. Mean $\pm \mathrm{SEM}$ is reported. Friedman statistical test was used $(* p<0.05)$ regulatory (Th2) in response to the autoreactive-cell injection or to the B cell depletion, accordingly to experiments performed using different protocols of $\mathrm{B}$ cell depletion (Weber et al. 2010).

The proliferative response of splenocytes is reduced when T cells loaded with NBR, either functionalized or not with anti-CD20 antibody, are injected in EAE mice (Fig. 8e). This may be due to a homeostatic effect of the injected $\mathrm{T}$ cells that, as we know from a previous work, tend to be less immunogenic after nanomaterial endocytosis (D'Elios et al., 2018). We may speculate that the less proliferating $\mathrm{T}$ cells and the simultaneous B cell depletion in the CNS are both responsible of the observed amelioration of EAE. In fact, B cell depletion may determine the failure of the compartmentalized antigen presentation and, consequently, a lack of sustainment to encephalitogenic $\mathrm{T}$ cells. This interpretation is supported by our results, that revealed a drop of $\mathrm{B} 220^{+}$cells in NBR-antiCD20-treated mice (Fig. 3o), suggesting that this treatment exerts an efficient B cell depletion. Conversely, anti-CD20 alone did not reach CNS in a sufficient therapeutic concentration, as demonstrated by the higher B cell counts within spinal cord infiltrates. Furthermore, the amelioration of EAE course finds supporting evidence in the evaluation of axons and neurons count in the spinal cord of mice groups, as our results showed a significantly higher percentage of $\mathrm{NeuN}+$ cells in the CNS of NBR-anti-CD20-treated mice compared to all the other groups (Fig. 6) and no axonal damage in the same group of mice (Fig. 7).

The exact mechanism of action of anti-CD20 is still unclear, but a combination of factors seems to occur (Glennie et al. 2007). Indeed, anti-CD20 seems to mainly act through the cell lysis induced by antibody-dependent cytotoxicity (ADCC) via monocytes, macrophages or Natural Killer (NK) FC $\gamma \mathrm{R}$ engagement (Boross and Leusen 2012), but the complement-dependent cytotoxicity (CDC) plays a pivotal role in the mechanism as well (Glennie et al. 2007), though several groups excluded the requirement of the complement in a wide range of rodent models (Hamaguchi et al. 2006; Nimmerjahn and Ravetch 2006; Uchida et al. 2004). However, it is likely that, in vivo, a synergic combination of effector mechanisms takes place at different times during antiCD20 treatment, depending on B cell dynamics, time frame of administration and perhaps also on targeted anatomic compartment (Boross and Leusen 2012). Of note, anti-CD20 antibody injected alone does not effectively reach the CNS, as shown by the higher and residual B cells amount in the spinal cord after treatment, probably linked to difficulty of large and hydrophilic molecules, such as monoclonal antibodies, in reaching CNS by crossing both $\mathrm{BBB}$ and $\mathrm{BSCB}$ (Kasinathan et al. 2015). Despite EAE model and MS are characterized by a partial loss of these biological barriers (Bennett et al. 2010), the total administered amount of monoclonal antibodies that are able to effectively reach the CNS is 

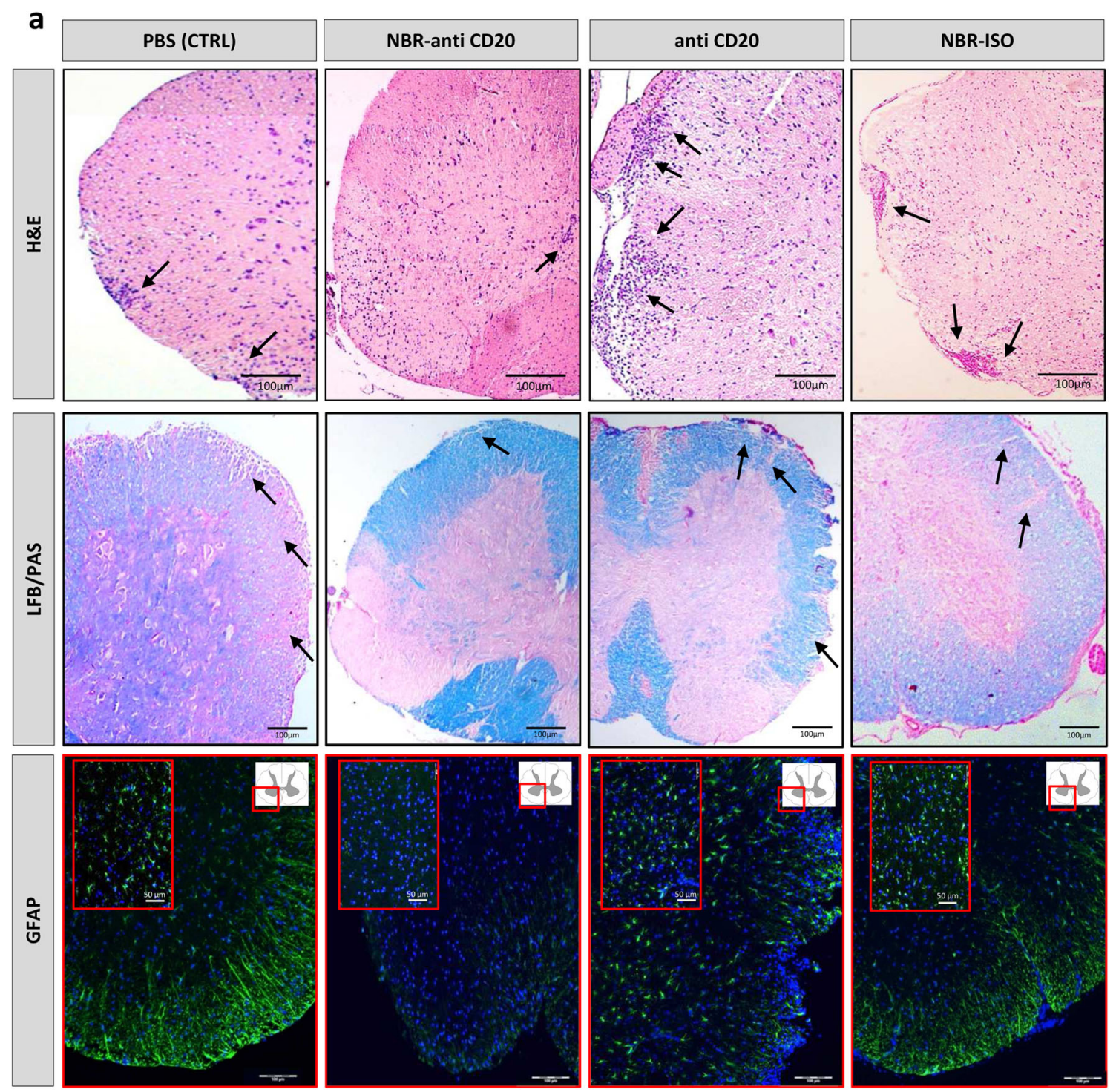

b
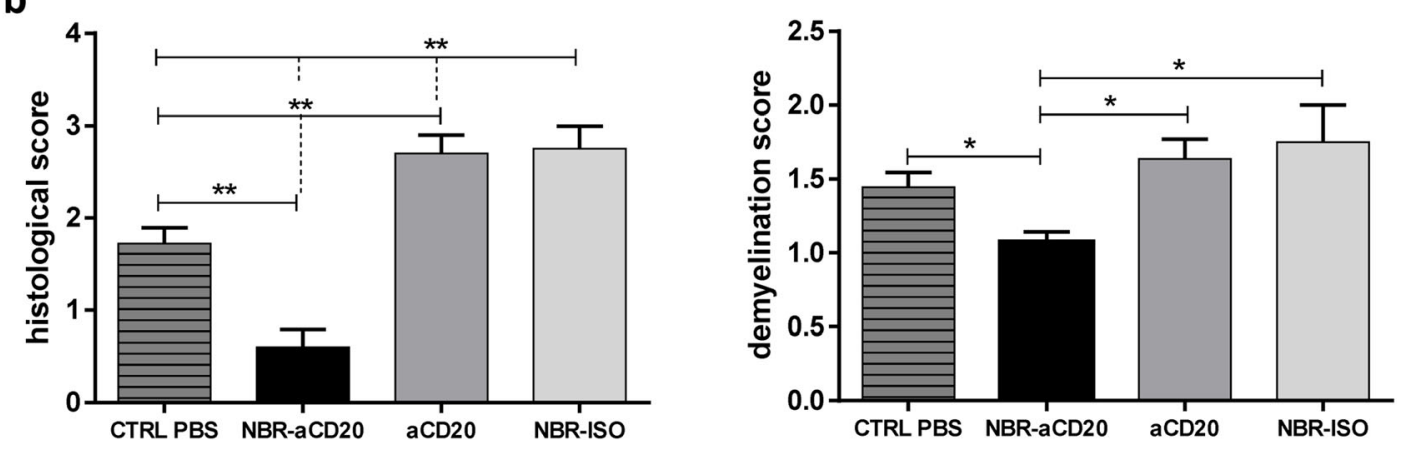

very low, specifically about $0.1 \%$ of serum concentration even if intrathecally administered (Rubenstein et al. 2003). For example, Komori et al. (2016) showed that the intrathecal administration of Rituximab in MS patients does not provide a successfully therapeutic depletion of B cells throughout the CNS tissue, limiting its action only to cerebrospinal fluid.

To sum up, this study showed that NBR-anti-CD20 enter T cells and that this complex is able to release in vivo the antibody both in the periphery and in the CNS of EAE mice. Our results stressed the need for an exact quantification, in the future, of the amount of antibody to bind to NBR and to release in the CNS to treat the disease. 
Fig. 5 EAE spinal cord pathology. a Panels show representative images, for each group, of spinal cord section after $H \& E$ staining for inflammatory infiltrates (black arrows, $4 \mathrm{X}$, scale bar $=100 \mu \mathrm{m}$ ), LFB/ PAS for demyelinated areas (black arrows; $4 \mathrm{X}$, scale bar $=100 \mu \mathrm{m}$ ) and GFAP labelling for astrogliosis (green $=\mathrm{GFAP}$, blue $=$ nuclei; $10 \mathrm{X}$, scale bar $=100 \mu \mathrm{m} ; 20 \mathrm{X}$, scale bar $=50 \mu \mathrm{m})$. b Histological score assigned for the inflammatory infiltrates (left graph) (according to Giuliani et al. 2005): score 0 for no infiltration, score 1 for foci of subarachnoid cell infiltration, score 2 for subarachnoid infiltration, score 3 for foci of parenchymal infiltrates and score 4 for diffuse and widespread parenchymal infiltrates. Right graph, demyelination score (Giuliani et al. 2005): 0 no demyelination; 1 refers to foci of demyelination superficial and proximal to the subarachnoid space involving less than $25 \%$ of the lateral columns; 2 represents foci of demyelination deep in the parenchyma involving over $25 \%$ of the lateral columns; 3 denotes diffuse and widespread demyelination areas. 25 tissue sections/mice were analyzed for each experimental group in two independent experiments. Mean \pm SEM is reported. MannWhitney statistical test was used $(* p<0.05 ; * * p<0.01)$

\section{Methods}

\section{NBR Synthesis and Functionalization}

Magnetite $\left(\mathrm{Fe}_{3} \mathrm{O}_{4}\right)$ nanoparticles (NBR) were synthesized as previously reported (Patent: Baldi et al., "Magnetic Nanoparticles functionalized with cathecol, production and use thereof", WO/2015 104,664) (Baldi et al. 2015). Briefly, $40 \mathrm{~mL}$ of NPFe suspended in diethylene glycol was sonicated for $1 \mathrm{~h}$ in an ultrasound bath and then a solution of [N-(3,4-dihydroxyphenethyl) dodecanamide (DDA)] (1.09 g, $3.2 \mathrm{mmol})$ dissolved in $120 \mathrm{~mL}$ of ethanol was slowly added to the glycolic suspension. The system was again sonicated for $1 \mathrm{~h}$ at room temperature. The solution was then diluted with $60 \mathrm{~mL}$ of ultrapure water, magnetically sedimented and dispersed in $90 \mathrm{~mL}$ of THF $\left(\mathrm{Fe}_{3} \mathrm{O}_{4}-\mathrm{DDA}\right)$. Then $440 \mathrm{mg}$ of PGLA-b-PEG$\mathrm{COOH}(43-3 \mathrm{kDa}, 9.6 \mu \mathrm{mmol})$ was dissolved in $10 \mathrm{~mL}$ of THF and then added to $90 \mathrm{~mL}$ of $\mathrm{Fe}_{3} \mathrm{O}_{4}$-DDA suspension (440 $\mathrm{mg}$ of $\mathrm{Fe}_{3} \mathrm{O}_{4}$ ). Fluorescent nanoparticles $\left(\mathrm{Fe}_{3} \mathrm{O}_{4}\right.$-DDA-Fluo $)$ were achieved by first adding a DMSO solution of Fluorescein 488-NHS (1.25 $\mu \mathrm{mol}$, amino reactive) to a solution of 4-aminobutylphosphonic acid $(1.25 \mu \mathrm{mol}$, a linker that can react with the carboxyl of the fluorochrome by its amino group and with the magnetic core by its phosphonic group) and left reacting under stirring for $3,5 \mathrm{~h}$. The mixture was then added to $90 \mathrm{~mL}$ of $\mathrm{Fe}_{3} \mathrm{O}_{4}$-DDA and the suspension was left reacting overnight at room temperature. The formation of NBR Fluorescent was achieved by the nanoprecipitation method: the organic phase was mixed to $900 \mathrm{~mL}$ of phosphate-buffered solution under vigorous stirring, maintaining the water/organic ratio $10 / 1$ with a constant removal of the resulting solution. The mixture was then purified, by washing with phosphate-buffered solution, and concentrated (by ultrafiltration, Pellicon $\mathrm{XL}$, cut-off $500 \mathrm{kDa}$ ) to a final volume of $150 \mathrm{~mL}$ (concentration: $0.3 \%(w / w)$ in $\mathrm{Fe} 3 \mathrm{O} 4)$, then filtered through a syringe filter (Millipore Sterivex, $0.22 \mu \mathrm{m}$, polyethersulfone membrane). Purified NBR have a diameter approximately of $45 \mathrm{~nm}$. Finally, chemical synthesis of NBRantiCD20 (UltraLeaf ${ }^{\mathrm{TM}}$ purified anti-mouse CD20, clone SA271G2, Biolegend,USA) or NBR-isotype control antibody (NBR-ISO) (UltraLeaf ${ }^{\mathrm{TM}}$ purified Rat IgG2b, $\mathrm{k}$ Isotype Ctrl Antibody, clone RTK4530, Biolegend, USA) complex was made through a double step reaction: PGLA-PEG-COOH iron oxide nanoparticles, exposing a $\mathrm{COOH}$, were activated in a mild acid environment $(\mathrm{pH} 5)$ with 1-Ethyl-3-(3-dimethylaminopropyl) carbodiimide (EDC), obtaining an O-acylisourea. Afterwards, Nhydroxysulfosuccinimide (Sulfo-NHS) was added at $\mathrm{pH} 5$, to improve efficiency and to create dry-stable (amine-reactive) intermediates. EDC couples Sulfo-NHS to carboxyls, forming an NHS ester that is considerably more stable than the O-acylisourea intermediate while allowing for efficient conjugation to primary amines at physiologic $\mathrm{pH}$ (ThermoFisher Scientific). Finally, at physiological $\mathrm{pH}$, anti-CD20 has been added to NBR, generating a stable peptide bond (very stable bond up to $\mathrm{pH}=1-2$, very strong acidic conditions and heating).

\section{In Vitro Test for NBR Uptake by T Cells}

T lymphocytes from naïve C57BL/6 mice were collected from draining lymph nodes and incubated for $2 \mathrm{~h}$ in $6: 1$ volume ratio with fluorescent NBR-anti-CD20 at $37{ }^{\circ} \mathrm{C}\left(5 \% \mathrm{CO}_{2}\right)$. Cell suspension was washed thrice with PBS for removing the excess of NBR-anti-CD20 outside the cells and then a drop of cell suspension was put on a glass slide (15,000 cells/spot) until dry. Then, spots were covered with paraformaldehyde 4\% (PFA 4) for 20 min for cells fixation. Glass slides were washed thrice with PBS and closed with mounting medium containing DAPI (Prolong Gold with DAPI, Life Technologies, USA) for fluorescence microscopy. The percentage of NBR positive cells was calculated on a total of 8 observed areas/slide $(10,000$ cells/slide $)$.

\section{Experimental Animals}

Female C57BL/6 mice (Charles River Srl, Italy) were bred in the CeSaL animal house of the University of Florence, in Makrolon cages, with free access to food and water and kept at $23{ }^{\circ} \mathrm{C}$ with a $12 \mathrm{~h}$ light/dark cycle. Every manipulation of the animals was executed according to the guidelines of the European community for animal care (DL 116/92, application of the European Communities Council Directive 2010/63/EU) and approved by the Committee for Animal Care (DGSAF, Italy, Authorization no. 514-2016-PR). 

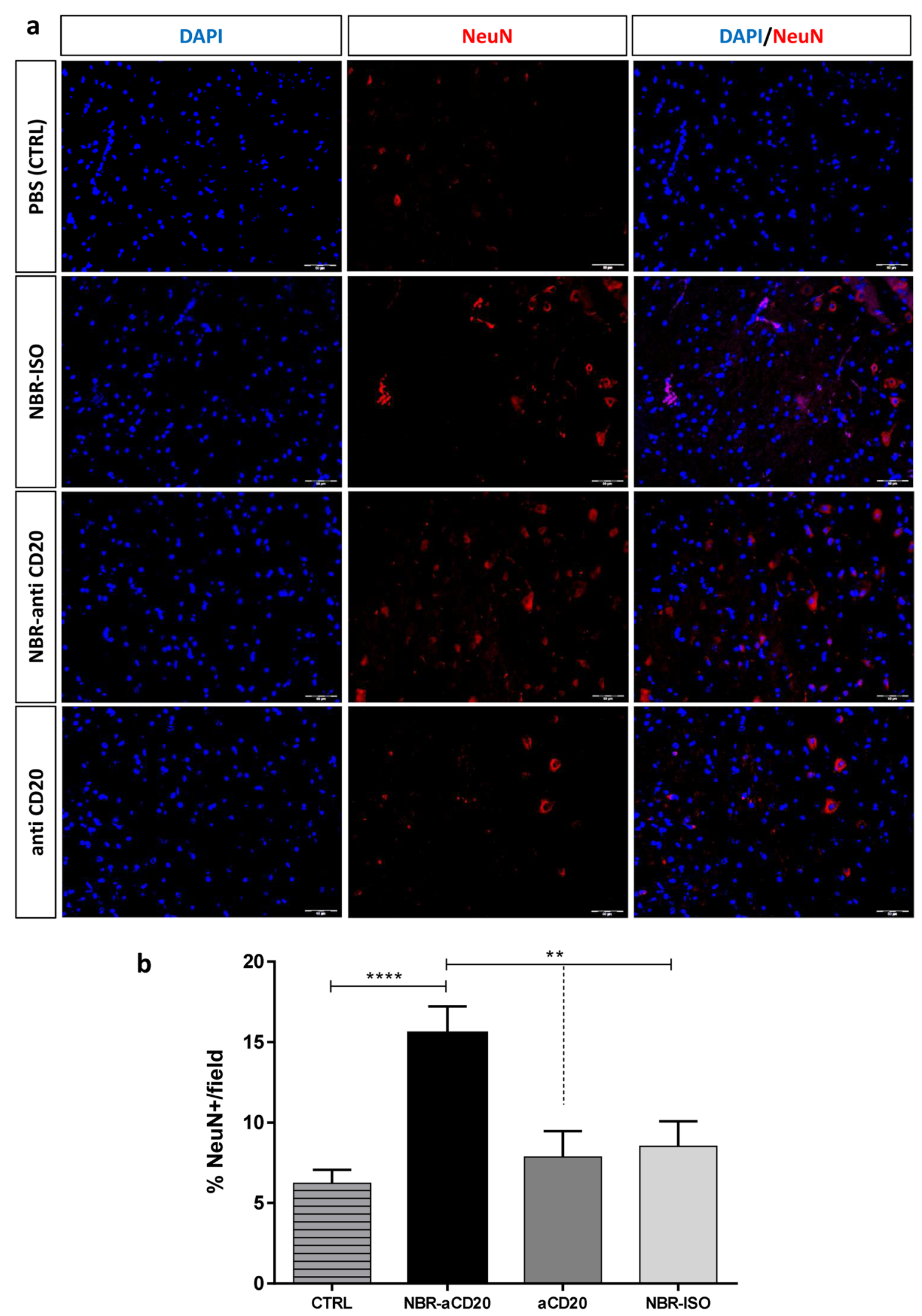
Fig. $6 \mathrm{NeuN}+$ quantification in the spinal cord of EAE mice. a Panel reports the immunofluorescence staining of $\mathrm{NeuN}+$ cells in the spinal cord of CTRL mice (first row), NBR-ISO-treated mice (second row), NBR-anti-CD20-treated mice (third row), anti-CD20-treated mice (fourth row). Spinal cord sections were labelled with DAPI to detect cell nuclei in blue (left column), NeuN to identify neurons in red (middle column) and DAPI/NeuN+ merge (right column). Magnification: 40X; scale bar = $50 \mu \mathrm{m}$. b Statistics of NeuN+ quantification (\% of NeuN+ cells/field) in the spinal cord of the four groups of EAE mice. Mean \pm SEM is reported. Mann-Whitney statistical test was used $(* * \mathrm{p}<0.01 ; * * * * \mathrm{p}<$ $0.0001)$

\section{Experimental Autoimmune Encephalomyelitis Induction}

EAE was induced in 8 to 10 weeks-old female mice by subcutaneous (s.c.) injection of $200 \mu \mathrm{g}$ of myelin oligodendrocyte g 1 y c o p rote i n M O $35-55$ pe p t id e (MEVGWYRSPFSRVVHLYRNGK, purity 85\%; Espikem, Florence, Italy) in Phosphate Buffer Saline solution (PBS, Carlo Erba Reagents S.r.l., Italy), emulsified with an equal volume of complete Freund's adjuvant (CFA, Sigma) supplemented with $7 \mathrm{mg} / \mathrm{mL}^{-1}$ Mycobacterium tuberculosis H37Ra (Difco Laboratories, USA). Bordetella pertussis toxin (500 ng) was administered by i.p. injection at days 0 and 2 post immunization (Merck, Germany). All the experiments with animals were performed blinded and mice were randomly assigned to the experimental groups. EAE-induced mice were scored daily for clinical signs of disease, according to the following scale: 0 ) normal mouse, no overt signs of disease; (1) limp tail or hind limb weakness but not both; (2) limp tail and hind limb weakness; (3) partial hind limb paralysis; (4) complete hind limb paralysis; (5) moribund state or death by EAE: sacrifice for humane reasons. Daily EAE score of mice groups is reported in Supplementary Table 1.

\section{Loading of MOG35-55 T Cells with NBR Nanoparticles}

Mononuclear cells were isolated from draining lymph nodes of immunized donor mice at 7 d.p.i. by mechanical dissociation on nylon filters with $70 \mu \mathrm{m}$ pores (BD Falcon). Cells were seeded in 96-well U bottom plates (Jet Biofil, China) at a density of $2 \times 10^{5} /$ well with $10 \mu \mathrm{g} / \mathrm{mL}$ of MOG35-55 in complete medium (RPMI $1640+10 \%$ fetal bovine serum $+1 \%$ penicillinstreptomycin $+1 \%$ sodium pyruvate $+1 \%$ L-glutamine $+1 \%$ Hepes Buffer, Sigma) for $72 \mathrm{~h}$. MOG35-55 reactive T cells $\left(2 \times 10^{6}\right.$ cells $\left./ \mathrm{mL}\right)$ were incubated with NBRanti-CD20 or NBR-ISO complex in a ratio of $6: 1$ for $2 \mathrm{~h}$ at $37{ }^{\circ} \mathrm{C}\left(5 \% \mathrm{CO}_{2}\right)$. Then, cells were washed three times with PBS and suspended at $1 \times 10^{6} / 150 \mu \mathrm{L}$ before i.v. injection in recipient mice.

\section{Mice Injection}

Mice were injected with 26G syringes (BD Plastipak ${ }^{\mathrm{TM}}$, USA) in the tail vein with $150 \mu \mathrm{L}$ of PBS, T-cells suspension loaded with NBR-anti-CD20 or NBR-ISO. NBR treated mice received $1 \times 10^{6}$ loaded $\mathrm{T}$ cells. Last group was injected with $250 \mu \mathrm{L}$ of anti-CD20 monoclonal antibody $(1 \mathrm{mg} / \mathrm{mL})$ alone (UltraLeaf ${ }^{\mathrm{TM}}$ clone SA271G2, Biolegend, USA).

\section{Histopathological and Immunofluorescence Evaluation}

Spinal cord samples were fixed with $4 \%$ paraformaldehyde (PFA) and paraffin-embedded and sectioned with a microtome in $5 \mu \mathrm{m}$ thick slices (D’Elios et al., 2018). Slices were stained with Hematoxylin and Eosin (H\&E), Luxol Fast Blue/Periodic Acid-Schiff (LFB/PAS), Perls (Bio-Optica, Italy) or Bielschowsky staining, following standard protocols. Histological score for inflammatory infiltrates was assigned according to Giuliani et al. (2005): score 0 for no infiltration, score 1 for foci of subarachnoid cell infiltration, score 2 for subarachnoid infiltration, score 3 for foci of parenchymal infiltrates and score 4 for diffuse and widespread parenchymal infiltrates. Evaluation was performed on 3 mice or more per group ( 25 slices each). The demyelination score was assigned following Giuliani et al. (2005) as follows: 0 no demyelination present; score 1 refers to foci of demyelination that is superficial and proximal to the subarachnoid space and that involves less than $25 \%$ of lateral columns; 2 represents foci of deep parenchymal demyelination and involves over $25 \%$ of the lateral columns; 3 denotes a widespread demyelination. Alternatively, selected slices were chosen for immunofluorescence. Briefly, slices were rehydrated with xylene for $5 \mathrm{~min}$ (renewing twice the solution) and with a descending degree ethanol series $\left(100^{\circ}, 90^{\circ}, 75^{\circ}\right.$ and $50^{\circ}, 3 \mathrm{~min}$ each) till deionized water (MilliQ). Afterwards, slices were immersed in a sodium borohydride $\left(\mathrm{NaBH}_{4}\right.$, Sigma) $1 \%$ solution for $10 \mathrm{~min}$, in order to quench intrinsic auto-fluorescence of formalin-fixed paraffin-embedded tissues. Then, the slices were left in citrate buffer (citric acid $10 \mathrm{mM}, \mathrm{pH}=6$; Sigma) at $95^{\circ} \mathrm{C}$ for $20 \mathrm{~min}$ and then cooled for $20 \mathrm{~min}$ at RT for antigen retrieval, permeabilized with PBS/ FBS 5\%/ Triton 0.3\% (Sigma, Germany) for $30 \mathrm{~min}$ at RT and labelled for $2 \mathrm{~h}$ in the dark at RT with anti-mouse FITC-CD45R/B220 monoclonal antibody (1:200, clone RA3-6B2, BD Pharmingen, USA) diluted in permeabilization buffer. Alternatively, slices were stained overnight with a primary GFAP rat anti-mouse monoclonal antibody (1:500, clone 2.2B10, Thermo Fisher Scientific, USA) or with NeuN Polyclonal Antibody (1:500, Thermo Fisher Scientific, USA), therefore with a goat anti-rat $\operatorname{IgG}(\mathrm{H}+\mathrm{L})$ Alexa Fluor 488 or a donkey anti-rabbit IgG $(\mathrm{H}+\mathrm{L})$ Alexa Fluor 594 secondary antibody (1:500, Thermo Fisher Scientific, USA). Slides were closed with glass coverslips using mounting medium containing DAPI (Prolong Gold with DAPI, Life Technologies, 
Fig. 7 Qualitative evaluation of the axonal damage in mice spinal cord by Bielschowsky staining. Figure reports the Bielschowsky staining on spinal cord sections in the four groups of EAE mice: CTRL (first row), NBR-ISO (second row), NBR-anti-CD20 (third row), anti-CD20 (fourth row) at $4 \mathrm{X}$ (left column; scale bar $=500 \mu \mathrm{m})$ and paired $10 \mathrm{X}$ (right column; scale bar $=$ $200 \mu \mathrm{m}$ ) magnification
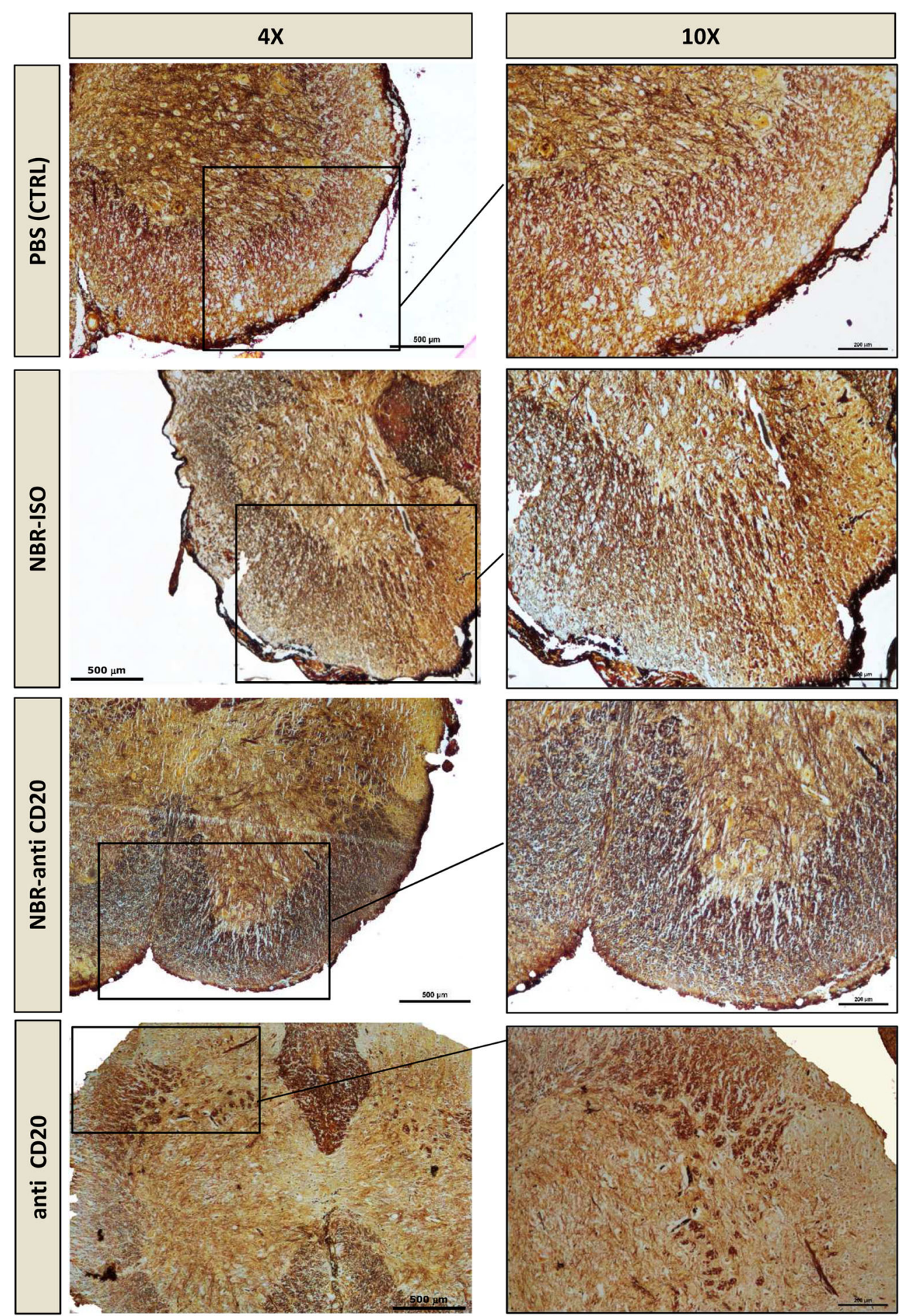

USA). Slides were observed by light or fluorescence microscopy (Leica Microsystems, Germany). The amount of B220 $0^{+}$and $\mathrm{NeuN}+$ cells in spinal cord was estimated manually (by ImageJ Software, NIH, USA), expressing the count as $\mathrm{B} 220^{+}$cells per $\mathrm{mm}^{2}\left(1 \mathrm{~mm}^{2}=\right.$ half spinal cord slice approximately $)$ or as $\mathrm{NeuN}+$ cells per field, on an average of 15 observed fields/ slide per mice group.

\section{Ex Vivo Evaluation of B Cell Depletion}

Spleen removed from EAE mice were put on nylon filters with $70 \mu \mathrm{m}$ pores (BD Falcon) and smashed by mechanical dissociation, followed by density gradient centrifugation (Biocoll, Biochrom AG). Mononuclear cells ring was manually isolated and marked with anti CD19 PE monoclonal antibody 
Fig. 8 Cytokine profiles of EAE lymph nodes $T$ cells and proliferative response of EAE spleen cells. Graphs report the level (pg/mL) of IFN- $\gamma$ and IL-17 cytokines in ex vivo $\mathrm{MOG}_{35-55^{-}}$ stimulated cells $(\mathbf{a}, \mathbf{c})$ or PHAstimulated cells $(\mathbf{b}, \mathbf{d})$. $\mathbf{e}$ Splenocytes proliferation was determined by ${ }^{3} \mathrm{H}$-thymidine incorporation assay and is expressed as $\Delta$ cpm (mean cpm observed in $\mathrm{MOG}_{35-55}$-stimulated cells mean cpm in not stimulated cells; $\mathrm{cpm}=$ counts per minute). Mean \pm SEM is reported. Mann-

Whitney statistical test was used $\left({ }^{*} \mathrm{p}<0.05 ; * * \mathrm{p}<0.01 ; \mathrm{ns}=\right.$ not significant) a

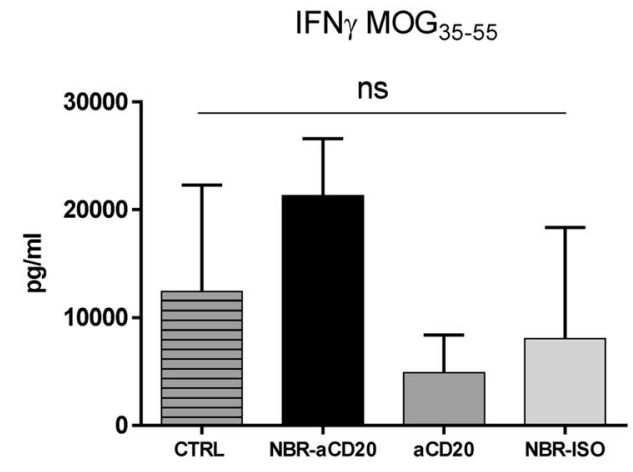

C

IL-17 MOG $35-55$
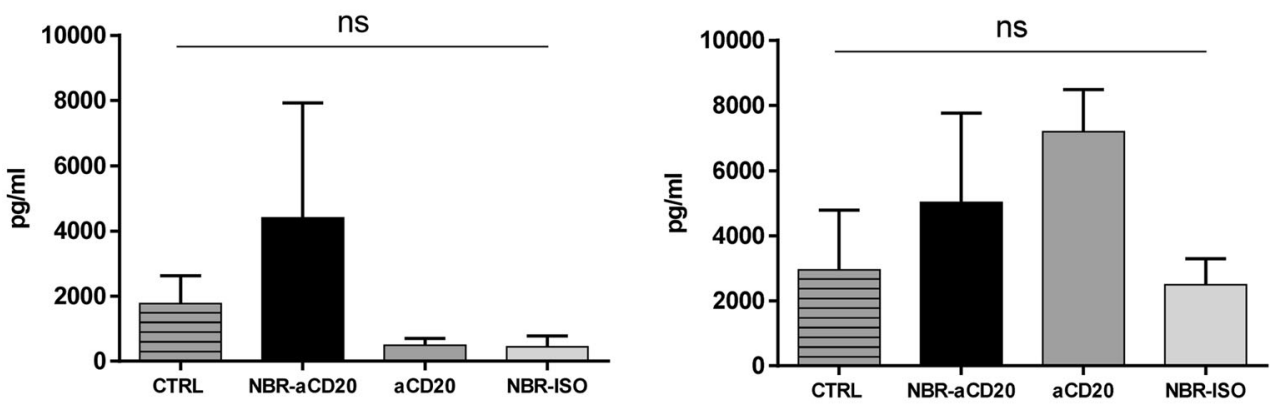

IFN $\gamma$ PHA

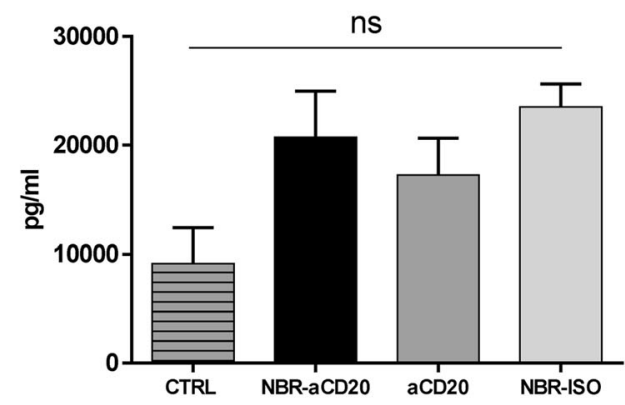

d

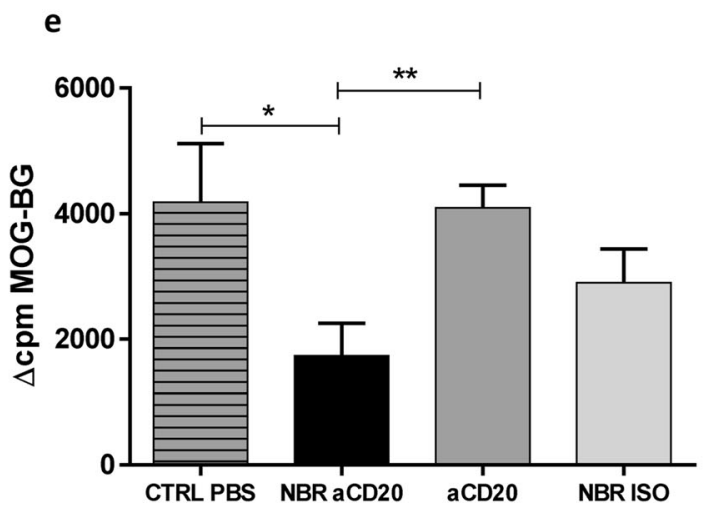

(Miltenyi Biotec, USA, 1:400). The evaluation of CD19+ cells was performed at 9 and 17 days post mice treatment by CyFLow Space flowcytometer (Sysmex Partec, Gemany) and FloMax® software (Sysmex Partec, Germany) and by LSR II Fortessa flowcytometer (BD Bioscences, USA) and by means of FACS Diva® software (BD Bioscences, USA) to acquire data, respectively. FlowJo® software (Flowjo LLC, USA) was used for the analysis.

\section{Cytokines Production}

Draining lymph nodes were removed, mononuclear cells were isolated as described above, cells were seeded in 96-well $\mathrm{U}$ bottom plates (Jet Biofil, China) at density of $2 \times 10^{5}$ cells/ well in complete medium (RPMI $1640+10 \%$ fetal bovine serum $+1 \%$ penicillin-streptomycin $+1 \%$ sodium pyruvate $+1 \%$ L-glutamine $+1 \%$ Hepes Buffer, Sigma), without stimuli, with MOG35-55 $50 \mu \mathrm{g} / \mathrm{mL}$ for $72 \mathrm{~h}$ or PHA $5 \mu \mathrm{g} / \mathrm{mL}$ for $48 \mathrm{~h}$. Incubation was performed by Heraeus 6000 (Heraeus, Germany) incubator at $37{ }^{\circ} \mathrm{C}$ and $5 \% \mathrm{CO}_{2}$. After incubation, supernatants were collected from each well and cytokines production was evaluated by Luminex ${ }^{\circledR}$ test (Merck Millipore, Germany), following manufacturer's protocol.

\section{Proliferative Response}

Cells isolated from spleen were seeded in 96-well $\mathrm{U}$ bottom plates (Jet Biofil, China) at density of $2 \times 10^{5}$ cells/well in complete medium, without stimuli, with $\mathrm{MOG}_{35-55} 50 \mu \mathrm{g} /$ $\mathrm{mL}$ for $72 \mathrm{~h}$ or PHA $5 \mu \mathrm{g} / \mathrm{mL}$ for $48 \mathrm{~h}$., as described for 
cytokines production evaluation; ${ }^{3} \mathrm{H}$-thymidine $1 \mu \mathrm{Ci} /$ well (Perkin Elmer, USA) was pulsed for $8 \mathrm{~h}$. Later, cells were harvested by means of Tomtec Harvester Mach III Cell Harvester (TomTec, USA) on a glass fiber filters discs and proliferative response was measured as counts per minute (cpm) with a scintillation Trimux Microbeta 1450 counter (Wallac). We considered the test positive when $\Delta$ cpm was $>1000 \mathrm{cpm}(\Delta \mathrm{cpm}=\mathrm{cpm}$ of stimulated wells $-\mathrm{cpm}$ of notstimulated wells).

\section{Statistical Analysis}

Statistical analysis was performed by GraphPad Prism ${ }^{\circledR}$ Software (GraphPad Software Inc., USA). Mann-Whitney or Friedman tests were used when appropriated. Statistical significance was considered when $p<0.05$.

Acknowledgements We are particularly grateful to Laura Ballerini for the critical revision.

Funding Information This work was in part supported by Regione Toscana, project INSIDE, FESR 2014-2020.

\section{Compliance with Ethical Standards}

Conflict of Interest Cericol Research Center Colorobbia (Italy) provided nanoparticles, named NBR, used in this work.

\section{References}

Baldi G, Ravagli C, Franchini MC, D’elios MM, Benagiano M, Bitossi M (2015) Magnetic nanoparticles functionalized with cathecol, production and use thereof [internet]. Available from: https://patents. google.com/patent/WO2015104664A1/en

Ballerini C, Baldi G, Aldinucci A, Maggi P (2015) Nanomaterial applications in multiple sclerosis inflamed brain. J NeuroImmune Pharmacol 10(1):1-13

Batrakova EV, Kabanov AV (2013) Cell-mediated drug delivery to the brain. J Drug Deliv Sci Tech 23(5):419-433

Batrakova EV, Gendelman HE, Kabanov AV (2011) Cell-mediated drug delivery. Expert Opin Drug Deliv 8(4):415-433

Bennett J, Basivireddy J, Kollar A, Biron KE, Reickmann P, Jefferies WA, McQuaid S (2010) Blood-brain barrier disruption and enhanced vascular permeability in the multiple sclerosis model EAE. J Neuroimmunol 229(1-2):180-191

Boross P, Leusen JHW (2012) Mechanisms of action of CD20 antibodies. Am J Cancer Res 2(6):676-690

D'Elios MM, Aldinucci A, Amoriello R et al (2018) Myelin-specific T cells carry and release magnetite PGLA-PEG COOH nanoparticles in the mouse central nervous system. RSC Adv 8(2):904-913
Dong X (2018) Current strategies for brain drug delivery. Theranostics. 8(6):1481-1493

Giuliani F, Fu SA, Metz LM, Yong VW (2005) Effective combination of minocycline and interferon- $\beta$ in a model of multiple sclerosis. $\mathrm{J}$ Neuroimmunol 165(1):83-91

Glennie MJ, French RR, Cragg MS, Taylor RP (2007) Mechanisms of killing by anti-CD20 monoclonal antibodies. Mol Immunol 44(16): 3823-3837

Goyal K, Koul V, Singh Y, Anand A (2014) Targeted drug delivery to central nervous system (CNS) for the treatment of neurodegenerative disorders: trends and advances. Cent Nerv Syst Agents Med Chem 14(1):43-59

Hamaguchi Y, Xiu Y, Komura K, Nimmerjahn F, Tedder TF (2006) Antibody isotype-specific engagement of Fcgamma receptors regulates B lymphocyte depletion during CD20 immunotherapy. J Exp Med 203(3):743-753

Kasinathan N, Jagani HV, Alex AT, Volety SM, Rao JV (2015) Strategies for drug delivery to the central nervous system by systemic route. Drug Delivery 22(3):243-257

Komori M, Lin YC, Cortese I, Blake A, Ohayon J, Cherup J, Maric D, Kosa P, Wu T, Bielekova B (2016) Insufficient disease inhibition by intrathecal rituximab in progressive multiple sclerosis. Ann Clin Transl Neurol 3(3):166-179

Li T, Dong H, Zhang C, Mo R (2018) Cell-based drug delivery systems for biomedical applications. Nano Res 11(10):5240-5257

Matsushita T, Yanaba K, Bouaziz J-D, Fujimoto M, Tedder TF (2008) Regulatory B cells inhibit EAE initiation in mice while other B cells promote disease progression. J Clin Invest 118(10):3420-3430

Nance E, Timbie K, Miller GW, Song J, Louttit C, Klibanov AL, Shih TY, Swaminathan G, Tamargo RJ, Woodworth GF, Hanes J, Price RJ (2014) Non-invasive delivery of stealth, brain-penetrating nanoparticles across the blood-brain barrier using MRI-guided focused ultrasound. J Control Release 189:123-132

Nimmerjahn F, Ravetch JV (2006) Fcgamma receptors: old friends and new family members. Immunity. 24(1):19-28

Rubenstein JL, Combs D, Rosenberg J, Levy A, McDermott M, Damon L, Ignoffo R, Aldape K, Shen A, Lee D, Grillo-Lopez A, Shuman MA (2003) Rituximab therapy for CNS lymphomas: targeting the leptomeningeal compartment. Blood. 101(2):466-468

Uchida J, Hamaguchi Y, Oliver JA, Ravetch JV, Poe JC, Haas KM, Tedder TF (2004) The innate mononuclear phagocyte network depletes B lymphocytes through fc receptor-dependent mechanisms during anti-CD20 antibody immunotherapy. J Exp Med 199(12): 1659-1669

Weber MS, Prod'homme T, Patarroyo JC et al (2010) B-cell activation influences T-cell polarization and outcome of anti-CD20 B-cell depletion in central nervous system autoimmunity. Ann Neurol 68(3): 369-383

Zhang T-T, Li W, Meng G, Wang P, Liao W (2016) Strategies for transporting nanoparticles across the blood-brain barrier. Biomater Sci 4(2):219-229

Zhou Y, Peng Z, Seven ES, Leblanc RM (2018) Crossing the blood-brain barrier with nanoparticles. J Control Release 270:290-303

Publisher's Note Springer Nature remains neutral with regard to jurisdictional claims in published maps and institutional affiliations. 